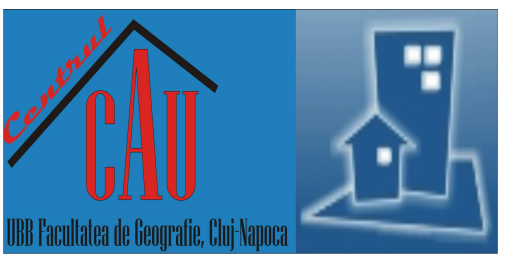

\title{
Exploring a Sustainable Strategy for Brownfield Regeneration. The Case of Halawah Farm, Amman City, Jordan
}

\author{
Amal ABED ${ }^{*_{1}}$, Majida YAKHLEF ${ }^{2}$ \\ * Corresponding author \\ ${ }^{1}$ Jordan University of Science and Technology, Department of Architecture, Irbid, JORDAN \\ ${ }^{2}$ Applied Science Private University, Department of Architecture, Amman, JORDAN \\ E-mail: arabed@just.edu.jo,m_yakhlef@asu.edu.jo \\ DOI: 10.24193/JSSPSI.2020.6.09 \\ https://doi.org/10.24193/JSSPSI.2020.6.09
}

K e y w o r d s: brownfield site, brownfield sustainable regeneration, urban renewal, contextual analysis sustainable guidelines, Jordan

\begin{abstract}
A B S T RA C T
Brownfield sites can be considered both a challenge and a lost opportunity, since they impact negatively the surroundings and regeneration potential. Yet, brownfield regeneration can have a major role in improving city's vitality and liveability due to its multiple positive impacts on cities in general and Amman city in particular. In the last few years, Amman has grown spontaneously and quickly with no sophisticated plan to consider city dynamics that produce brownfield land. Therefore, this research aims to explore the opportunities of a comprehensive regeneration approach by understanding the complexity of a brownfield site. The work particularly addressed Halawah Farm brownfield area (in Amman municipality, which includes architectural and urban settings and currently it is an abandoned facility within a vibrant zone of the city. Contextual analysis for the research setting along with SWOT analysis helped us explore the potentials and challenges of this site. As a result, the development of a conceptual plan and application guidelines were elaborated to be employed in transforming a problematic space into a liveable one. This would be achieved by cleaning-up of site, reusing abandoned area, stimulating development opportunities, and involving locals. That is, sustainable vision considered as a tool for site rehabilitation, it especially has environmental, social, and economic focus. As a matter of fact, this study could be a good tool to simplify the paradox and complexity of this issue under study. Consequently, this will be translated into strategic plans and design guidelines for regeneration brownfield sites to enhance urban competitiveness and reduce urban sprawl.
\end{abstract}

\section{INTRODUCTION}

Most urban areas are facing with the problem of abandoned sites due to economic growth and industrial restructuring along with continuous dependence on greenfield development. This affects negatively resources management by producing sites known as "brownfield", which is defined by several institutions and scholars as abandoned, derelict, vacant, idled, or underutilized industrial and commercial facility because of actual or perceived contamination or other obstacles (USEPA, 1997; APA, 2005; Alker et al, 2000). Therefore, it is necessary to develop a strategy that pursues an ideal intervention aiming not only to improve the conditions at physical level but also to extend and include all dimensions (environmental, socio-cultural, and economic). Since brownfield regeneration is a win-win strategy and plays a major 
role in community development, there is a growing interest around this theme with emphasis on achieving sustainable development. Especially, it encompasses valuable opportunities regarding several dimensions such as controlling urban sprawl, decreasing pressure on greenfield sites, reducing risk on public health and safety, renewing urban cores, retaining of existing jobs, and counteracting negative social stigmas associated with such sites. This means bringing long-lasting life back to the brownfield sites, surroundings, and local community by considering it as a potential free space for urban renewal (De Sousa, 2002; Greenberg, 2001; Baskaya, 2010; Kurtovic et al, 2014; Bardos et al, 2016). Sustainability is an essential prerequisite that guarantees the continuity of viable solutions for brownfield sites. Especially, regeneration of such sites is a complex process because it aims to restore a balance between environmental, social, and economic components within a holistic approach. At environmental level, regeneration aims to enhance the general appeal of a place by improving both built and natural environment along with infrastructure. In terms of social equity, it aims to improve life quality of the community by developing skills through offering programs/activities for youth, women, and other social groups. This may enable them benefit from opportunities within a strengthened social network. Also, regeneration aims to increase economic competitiveness by creating more local jobs and prosperity through the deployment of local resources. Therefore, the sustainable redevelopment of brownfield sites is a holistic integrated approach with wide range of opportunities that may solve several complicated issues related to economic, social and environmental aspects (Roberts and Skyes, 2000; Nogués and Arroyo, 2016).

Currently, brownfield regeneration occurs throughout the world as a response to the growing consensus on its great benefits and opportunities. Several projects have effectively integrated the reclamation of brownfield land with collective economic action through implementing the Public-Private Partnership (PPP) model. This absolutely required establishing institutional set up to unify efforts, and activate the coordination of all related stakeholders by engaging local communities and involving active groups to become the drivers of change in their neighbourhoods (UNEP, 2004; Chen et al, 2016).

Such a strategy was widely implemented in Europe and North America. For example, United Kingdom paid a total of 560 million Euros in 2005 in the partnership between public and private sectors for the redevelopment of the Waterfront area of Liverpool, UK. The development consisting of mixed-use areas, business and leisure have been built in brownfield sites and unused territories, on the principle of the PPP. This project created about 2,500 new jobs with a new environmental aesthetic image while also preserving the cultural heritage and city's identity by renovating some of the old buildings. A similar approach was implemented in Sarajevo, Bosnia and Herzegovina, which created liveable places from problematic sites, and much more success was achieved by several projects all around the world (Rădulescu, 2016; Nogués and Arroyo, 2016; Rosén et al, 2015; Gegic and Husukic, 2017). Generally speaking, the redevelopment and regeneration of brownfield sites should be achieved by complying with sustainability principles to solve the social, economic, and environmental issues integrally.

Based on that, a well-defined framework and flexible policy for developing such sites is a serious need. This requires the acknowledgement of the existing situation along mapping of the problems and opportunities. This can be achieved through contextual analysis, which aims to identify goals and objectives, followed by defining and proposing an action area together with intervention stages to guarantee a continuous development. By this approach brownfield sites are not considered as a harmful issue that needs to be solved but as areas with potentials and opportunities, which require a clear policy to facilitate management and operation (UNEP, 2004; APA, 2005; Frantal et al, 2013; Kurtovića et al, 2014). However, Jordan unfortunately does not have a clear policy that would regulate this kind of development, although Amman (the capital of Jordan) is an old city and has many abandoned and underutilized facilities and sites. Therefore, it is necessary to discuss a comprehensive sustainable framework for brownfield land and urge the government to adopt such a strategy.

Brownfield sites dispersed over Amman appeared due to the sprawl of the city. Tarawneh, (2015) discussed the typology and distribution of brownfield land trying to highlight the significance of this issue and urging decision-makers to respond. Since Amman city presents a severe lack of open spaces, AlJabi (2016) discussed the possibilities of an interim use for such zones that resulted from incomplete colossal buildings due to halted investments. Moreover, another study highlighted the government's initiative to develop military sites as a strategy for creating jobs along with economic development (Bagaeen, 2006). But, unfortunately, none discussed a possible process of regeneration within the sustainable framework. Therefore, there is a serious need to discuss it comprehensively aiming to propose suitable guidelines with a clear definition of intervention criteria, which would cope with the community needs and desires. This research aims to provide policy makers with some proposed guidelines, which are supported by a case study and principles of implementation for brownfield site regeneration. Also, our study suggests a methodological approach for renewing such sites based on both longitudinal and cross-sectional observation, and contextual analysis along with interdisciplinary 
investigation. We hope this may enhance the process of brownfield land regeneration and encourage investors and stakeholders to implement such initiative.

\subsection{Amman brownfield site}

This study focuses on the city of Amman (the capital of Jordan), its history being related to several ancient civilizations such as Stone Age (7500 BC), Ammonite, Assyrian, Persian, Greek, Roman, Byzantine, Islamic and Ottoman era. Its modern history began in 1878, when the Circassians were relocated and settled there. Moreover, Amman received a series of immigration flux because of the conflicts and protests in its surroundings. It started with the Palestinian refugees in 1948 and 1967 due to Israel-Palestinian conflict, followed by the Lebanese civil war that caused more immigrant flows to the city. Then, its population increased dramatically through the Iraqi-Kuwait conflict in 1990 and the recent ongoing skirmish in both Iraq and Syria (Al-Rawashdeh and Saleh, 2006). Based on that, the city of Amman has expanded to include 22 districts with a total area of (approximately $700 \mathrm{~km}^{2}$ ), populated by 4 million residents (Jordan Department of Statistics, 2016). Due to the rapid growth along with a poor planning strategy, Amman has suffered from several abandoned and underutilized sites of various uses such as industrial, commercial, military, infrastructure. They are administered by public entities (army, or government), private owners, or NonGovernmental Organizations (NGOs). Moreover, the size of sites ranges from small (of around $100 \mathrm{~m}^{2}$ ) up to a maximum of about a hundred thousands of square meters. This was highlighted by Yakhlef and Abed (2019) who discussed the typologies of brownfield sites in terms of size, use, level of occupancy, and physical condition. This study showed more than 150 brownfield sites, which together occupy more than $800,000 \mathrm{~m}^{2}$, all concentrated in the old districts of the city. Fortunately, most of these sites have no real or perceived contamination problems due to their original use, in which case less than $20 \%$ had an industrial use.

This should be seen as an incentive to rehabilitate the abandoned and underused sites. Despite this, brownfield land rehabilitation is not a part of Amman urban planning dialogue and legislation or local policies. The city plans $(1955,1968,1987$, and 2006) have not yet not acknowledge it, and there is no official framework for the regeneration of such sites. Therefore, it is necessary to discuss it in a comprehensive sustainable framework trying to propose a regeneration guiding plan for such zones. Especially, these typologies have unique reasons and prospective issues for development that may relate to the location potential as city centre, or the proximity to a main transportation axis, which would facilitate regeneration and renewal.

\section{THEORY AND METHODOLOGY}

Brownfield regeneration requires a comprehensive understanding for the factors that may affect the potential of evolution and development, and subsequently, a transdisciplinary approach suitable to initiate the process for solving the existing issues. This would provide clarification for brownfield regeneration within a sustainable framework by emphasizing on the development potential and competitiveness.

Based on that, a qualitative research was adopted in conducting this study, since it was a project based research. This was achieved through the following steps:

A). The comprehensive understanding of the selected brownfield site through contextual analysis. This was accomplished by responding to several questions, namely:

a). What is the significance of the brownfield site location? This was answered through the location map showing the city districts along with adjacent neighbourhood. Also, by using the circulation map at different scales, we showed the hierarchy of streets and pedestrian paths to reveal accessibility.

b). What is the history of the selected brownfield site? This could be comprehended through studying several satellite images/maps over time to conclude the growth pattern for the brownfield site and its surroundings.

c). How had this brownfield land been used? This was clarified through studying land use and tracing changes over time for brownfield site and its surroundings.

d). What is the architectural identity? We studied the visual character through panoramic views from the location to surroundings and vice-versa. Also, we documented the existing facilities and the natural heritage.

e). How stakeholders interact with the brownfield site, and what do they need/expect? And what are the important cultural features or remarkable local customs? This was realized by interviews with owners, community and agencies that have direct relations with locals and trying to improve their life quality. This analysis may facilitate solving the negative issues and inspire designers/planners to create a sustainable framework.

B). The SWOT analysis (Strengths, Weaknesses, Opportunities, and Threats) that highlights multi-variables measures to better prescribe possibilities of regeneration/development options and provide a chance for exploring the limitations and future obstacles at both meso and micro scale. This may help to focus on the objectives that maximize opportunities and minimize threats along with a better vision for the revitalization process that implies synergy of theory, professional practice, and community. 
C). The development of design guidelines for regeneration strategies of the selected brownfield site based on contextual analysis.

Guidelines should be responding to problems and potentials of the brownfield land by considering various levels of sustainable development. This can be achieved through corresponding strategies at sociocultural, economic, and environmental levels.

\subsection{Contextual analysis}

The case study was selected according to the following criteria: a) significant location such as the proximity to city centre and transportation network; b) availability of social capital, which is represented by the local community's interest in regeneration along with public initiatives; c) economic potential represented by investment and employment opportunities, in addition to existing incentives such as decent quality of structure for the existing buildings; d) heritage value - if the site has some natural heritage like old trees/other green covers and structures with architectural value; and e) additional facts such as data availability, ownership status, and governmental initiative for development.

Based on that, Halawah farm was selected as the case study brownfield site, for which the abovementioned aspects will be discussed below. Halawah farm is located in Arjan neighbourhood within Al-Abdali district, as shown in Figure 1 (P. 1 - P. 4). It can be considered as an island surrounded by streets from all sides.

On northeast side, it has a vital junction of two major highways (Al-Shaheed St. and Jordan St.). Moreover, it is surrounded by local streets from other sides, which suits it to be an entry zone despite the narrow and poor maintained sidewalks as shown in Figure 1 (P. 5 \& P. 6 ).

Halawah farm is located within a vital dense area with several types of facilities of various uses, namely residential, commercial (shops, car dealers, and offices), institutional (schools, and governmental institution), medical services (private hospital), religious (mosque), and others, such as transportation hub and park. However, in 1940, it was located on the fringe of the city, and served as a suburb for the city. The farm land is of about $25,000 \mathrm{~m}^{2}$; it was originally built to wrap tobacco in 1952. Then, in 1972, barns for cows were added along with other associated function such as food grinder, workshops (carpentry, and black smith), and housing for workers. In 2002, poultry barracks and eggs incubators were built. Finally, in 2007, the municipality shut it down since it was situated within the city limit, where agricultural activities are usually not allowed.

Based on that, a huge land parcel with 21 buildings can be mainly considered as abandoned/underutilized. However, only two buildings are used as private residence for the owner along with some rooms occupied by workers who used to be working in the facility. Moreover, a small room was used as an office, a barrack was used as a library, and another building was used as a pigeon coop as shown in Figure 1 (P. 7 - P. 10).

Despite that most of facilities are deteriorated or damaged, for instance some buildings have no roof along with major structure failure as shown in Figure 1 (P. 11), the site includes several valuable green plots where we can find more than 50 year old trees in addition to some rare native shrubs as shown in Figure 1 (P. 12).

The site also has a significant visual character to the city since it has a potential for panoramic views from Jordan St. since it provides great views especially from the south side, which could improve aesthetic value. This can be ensured through connecting the site with the surrounding landmarks and social/cultural nodes, especially since several of them are in close proximity to the site, as shown in Figure 1 (P. 13 \& P. 14).

\subsection{SWOT Analysis}

Halawah farm benefits from many advantages and opportunities to encourage redevelopment as shown in Figure 2.

The strength factors are:

a) at economic level: vital location with major transportation access in addition to diverse functions/ activities around the site such as schools, parks, transportation hub, car dealers, governmental services, hospitals, and residential buildings;

b) at social level: some residents are still living on the site and are willing to involve and participate in the development process;

c) at environmental level: natural diverse vegetation that include different types of trees and shrubs along with availability of several shaded corridors and pedestrian paths in the site.

Regarding the opportunities that can be achieved, we mention:

a) providing public space for the neighbourhood neighbouring communities since it is surrounded by a residential area;

b) rehabilitating the site in a nostalgic way by reusing it as an urban farm or for other agricultural activities;

c) reusing the built facilities for diverse cultural and economic activities, such as gallery, workshops, shops, café and many others that may provide job opportunities for the local community, even though there are a couple of structures that have to be demolished.

On the other hand, there are many weaknesses and threats that may challenge the redevelopment. 


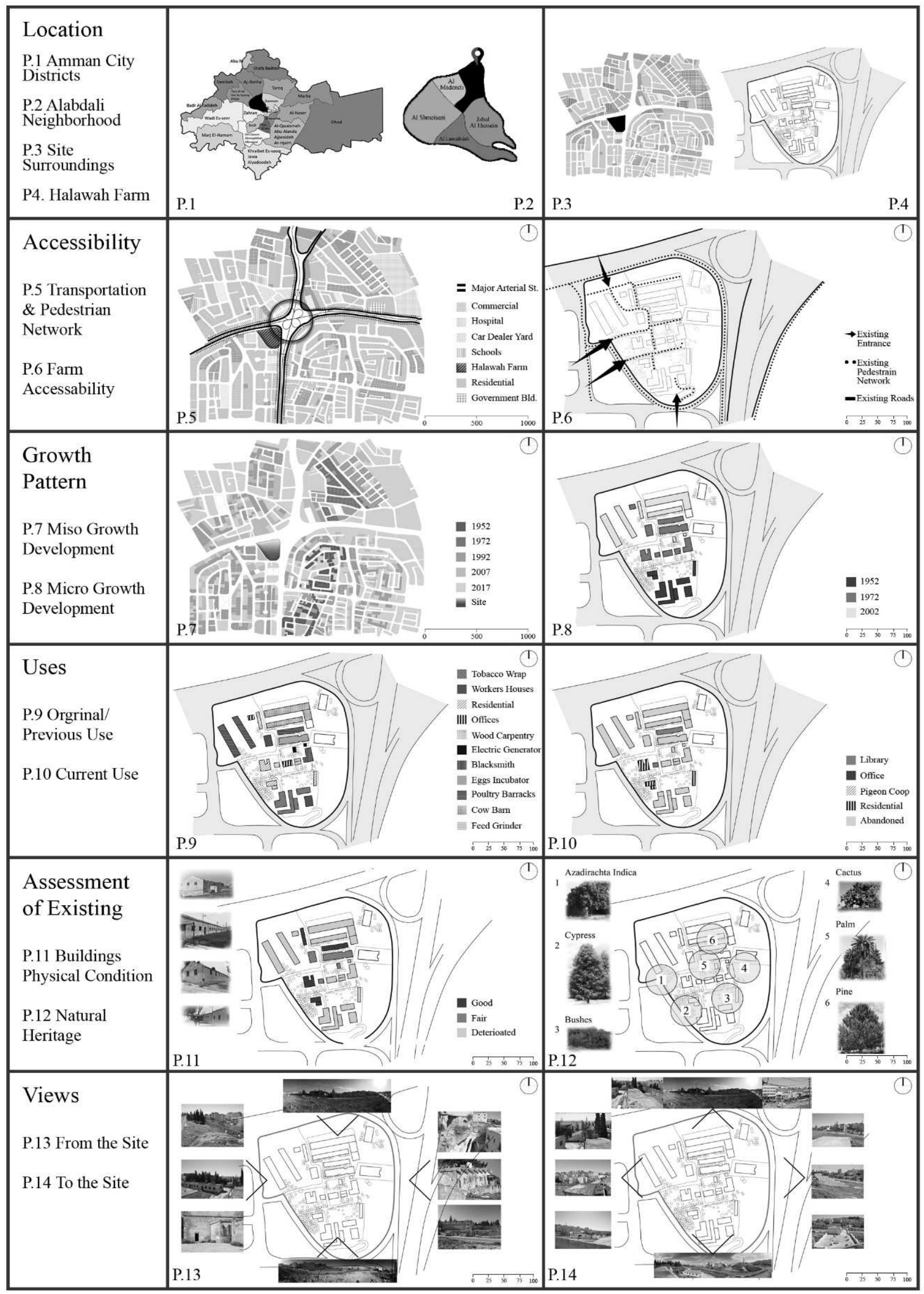

Fig. 1. Contextual Analysis. 
A: Miso Scale SOWT Analysis
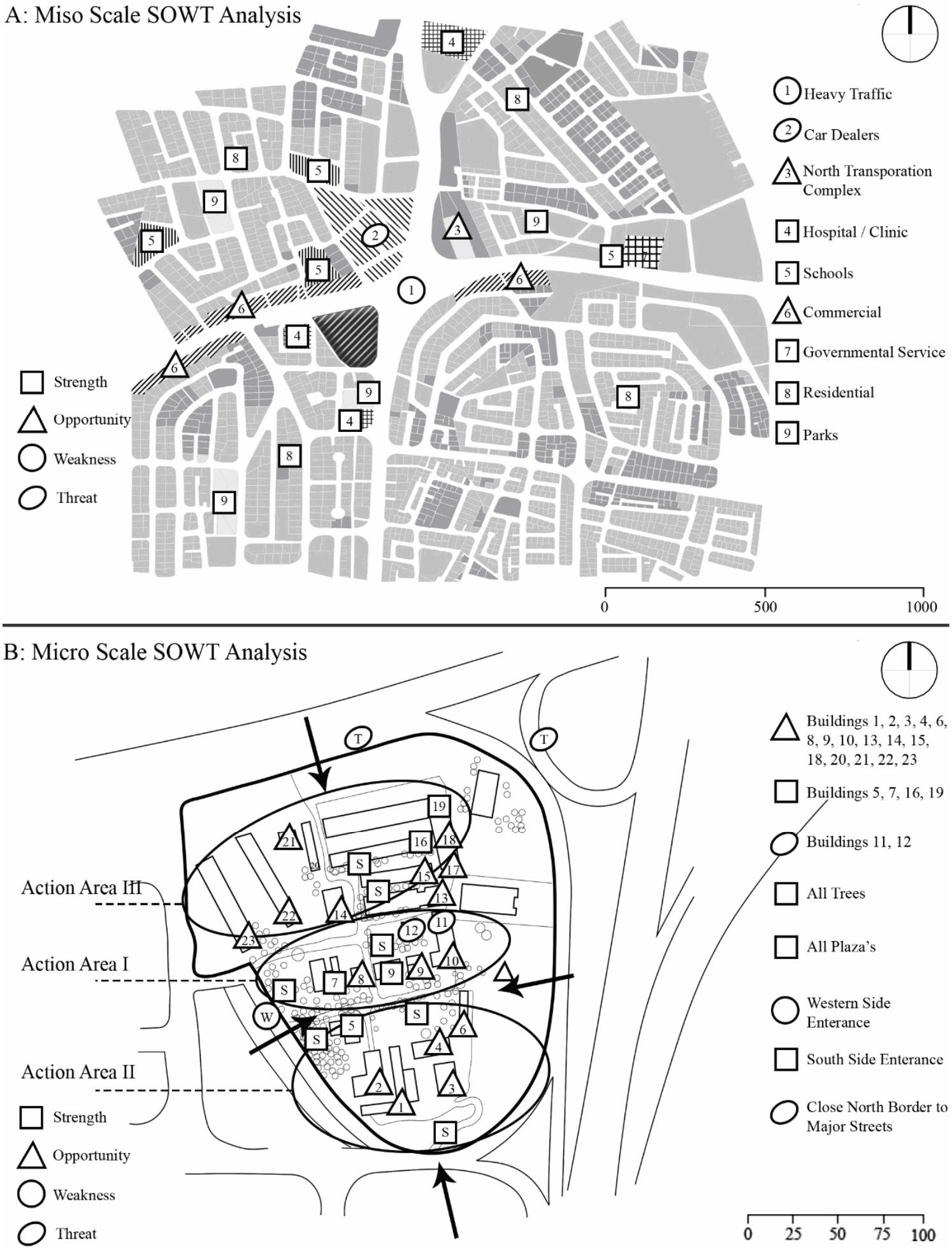

Fig. 2. The SWOT Analysis. following:

The weaknesses are represented by the

a) site located within a congested zone with heavy traffic jam that may be getting worse in the future;

b) poor connectivity with surroundings especially in the case of the entrance from Al-Shaheed St. that has poor pedestrian environment; c) abandoned facility with low maintenance that leads to anti-social behaviour along with concentration of garbage at the site;

d) damaged and poor structural quality of the facility may eliminate rehabilitation or the reuse of the buildings.

Also, more threats may diminish the redevelopment success, namely: 
a) increased traffic due to the municipality future plan of increasing density by replacing car dealers buildings with residential towers;

b) on the implementation of the municipality land use plan by transferring the northern section of site that faces the major streets into a commercial facility and the other part into a residential one without considering the surrounding's needs for public open spaces.

Having these, it becomes obvious the need for integrated strategies to guide regeneration and achieve development at socio-cultural, environmental, and economic levels. This can be started by defining three action areas: the first zone, which is located in the centre of the farm, the second zone is that facing AlShaheed St., which is regulated as for commercial use, and the third action area, which is in close proximity to the residential neighbourhood.

\section{RESULTS AND DISCUSSION}

\subsection{Design guidelines}

The main regeneration strategy is to develop the site by creating a village in the heart of the city, thus revitalizing its rural image. This theme is not only nostalgic to the site, but it would be a refreshing lung within the city. This should be achieved within a comprehensive vision on several levels.

At environmental level:

a) promote connectivity between the site and surroundings to enhance accessibility. This can be achieved through fostering external and internal connection by setting up different types of entrances for vehicles and pedestrian such as pedestrian bridge, tunnel and walking way;

b) reuse the existing facilities with aesthetic value to eliminate demolishing and enhance the reuse of existing artefacts as antiques and pieces of art work;

c) reduce new constructions as much as possible to maintain green land and eliminate rigidity;

d) conduct access to city skyline and scenic views.

At social level:

a) enhance social equity through creating sustainable social cultural hubs. This can be achieved by providing places for interaction such as galleries, cafes, entertainment centre and many more;

b) involve local community in the elaboration of regeneration strategies by encouraging them to participate in development plan;

c) make the facility open to public by hosting cultural events/tours and artistic/educational activities to maintain occupancy and enhance public creativity in promoting the place.

At economic level: a) creating a bazaar, a market for events (private events as birthday, wedding, corporate meetings, etc), along with the possibility of reusing the site for media making (for instance, two TV shows were filmed there recently;

b) create job/business opportunities for the locals to improve their economic status.

Based on the SWOT analysis and design strategies, three action areas are proposed. As shown in Figure 2, the first action area is the site entrance from residential neighbourhood side that aims to provide access for both pedestrians and vehicles. Works should be concentrated on widening the streets for low speed cars by using traffic calming techniques (paving streets with bricks and using pumps before entrance).

The abandoned residence (building 1) should be rehabilitated to be a lobby and reception by removing the exterior facade and some interior walls to make it more welcoming for the visitors. The adjacent building (building 2) should be turned into offices for administration. Then, visitors will be directed to the main plaza (space 3), which consists of a major open space surrounded by five one-story buildings from three sides. The structure in the middle of plaza (building 4) should be demolished to make it more spacious.

The abandoned one-story building in the north side (building 5) should be rehabilitated and reused as an internet café serving organic herbs, its roof reused to be a sheltered seating area accessed by an external steel staircases.

The abandoned structure on east (building 6) should be rehabilitated and set as a souvenir shop. The other two separated structures in the south (building 7) that are inaccessible from plaza should be connected together by constructing a solid wall to use the whole façade as a screen for open air theatre. The plaza would be designed to have a high level of flexibility for event planners. So, it could serve as an outdoor meeting area, private party, and others. Also, it could become a central point wherefrom visitors would be directed to other zones.

The second action area, which is located south of the site, it serves as a memory stimulus to the former story about agricultural development on site. This zone is connected with the surroundings through a pedestrian bridge to link the site with community on the eastern side. Therefore, the stepped rooms (building 8) should be rehabilitated and reused to become an information centre for agricultural schools.

The plaza (space 9) behind it would be used as crops garden, while the building on the western side (building 10) would be reused for theoretical classes and seminar rooms. The crops garden would be divided into several small plots to satisfy the school needs. Extra lots will be offered for the community's seniors to practice farming and share their experience with students. The linear building on south part (building 11) 
would be reused as a restaurant for traditional healthy food serving scholars, community, and visitors. The abandoned barrack in the south (building 12) would be reused as a bazaar connected with the plaza in front of it, further used as open air bazaar where community could sell their crops.

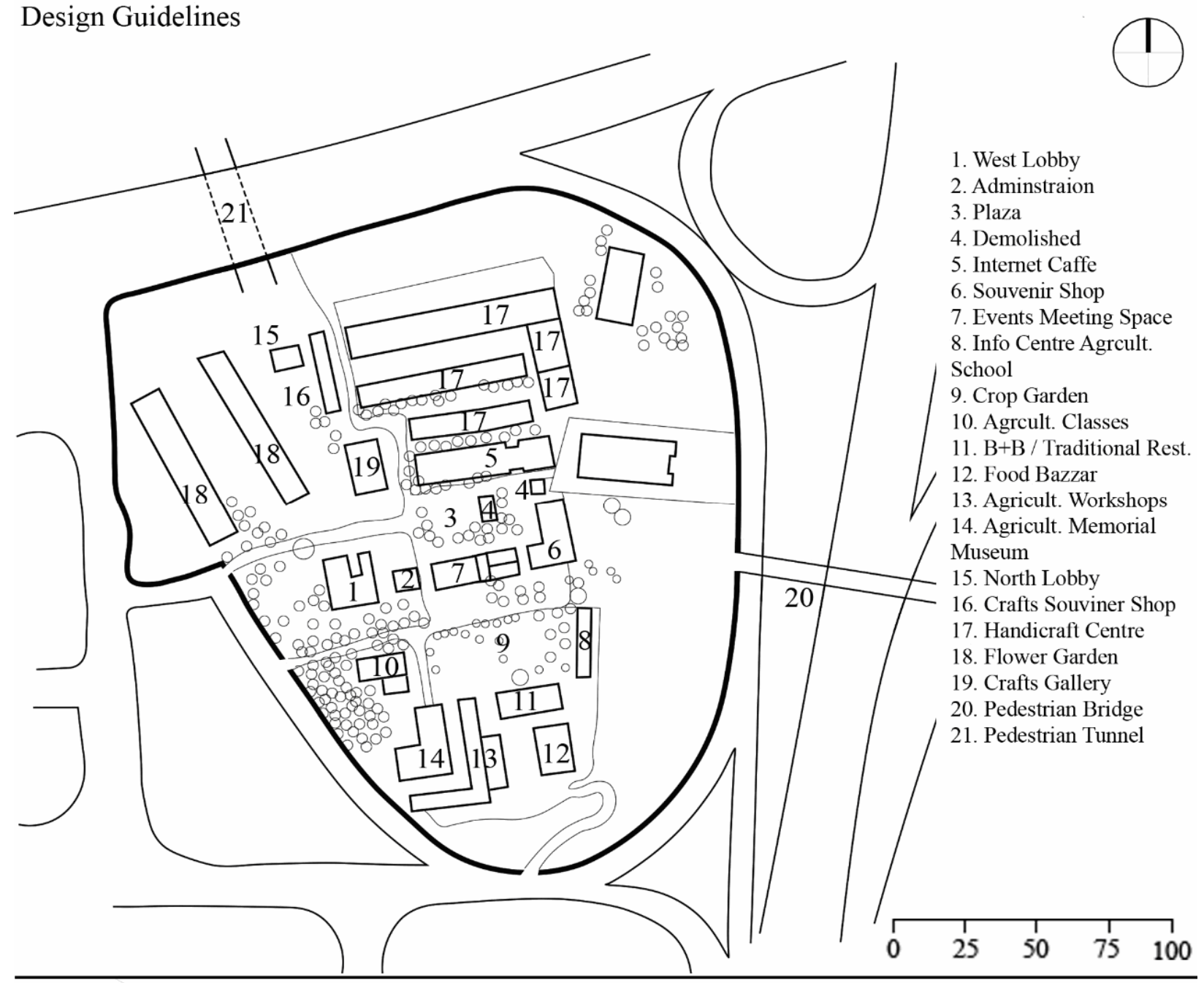

\section{Design Proposal}

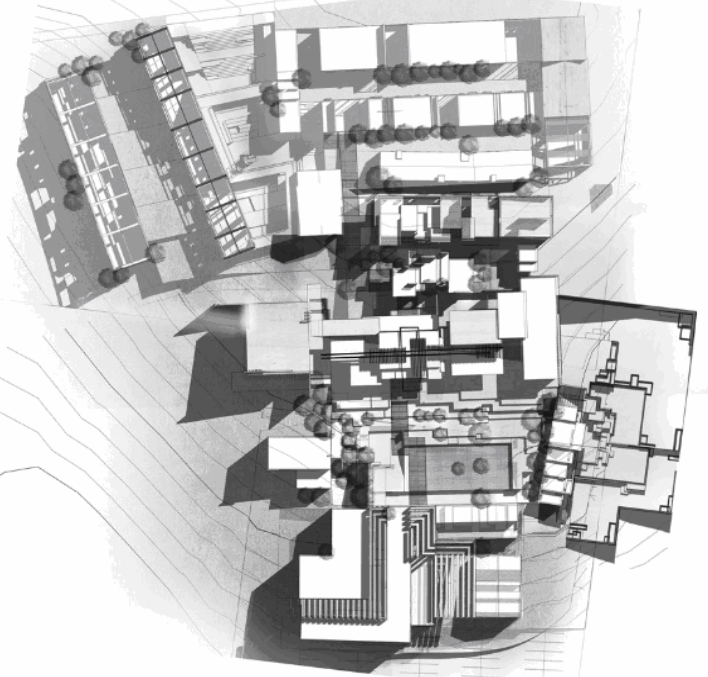

Fig. 3. Proposal of functional components.

The two adjacent three-storey buildings would be reused as a workshop for agriculture (building 13) and a memorial museum (building 14) for the
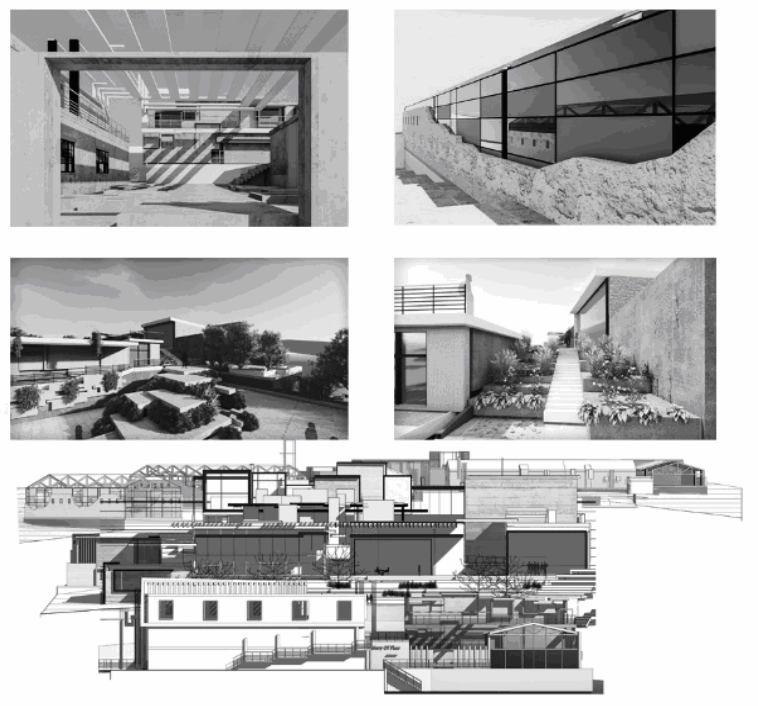

preservation of agricultural heritage by rehabilitating several existing artefacts along with memorial photos and documents about the site. 
This space would be redesigned to include several levels and an outdoor zone between both structures and make a connection between the two buildings through a split level. Also, a panoramic elevator should be added to connect the ground floor with the roof, which may be used as a rest area with a direct access to main plaza.

The third action area, which is located at top northern part of the site, could be accessed from the surroundings through a tunnel to avoid heavy traffic on Al-Shaheed St. The tunnel would end at building 15, which would be turned into an entrance lobby hosting advertisements for the handicraft centre and flower garden. The lobby should be extended to include souvenir shops in linear structure (building 16). This action area should be divided into two sub-zones, the first sub-zone, located in north-eastern part of the site, would have commercial function, consisting of three linear strip building (building 17), proposed to be a centre for traditional handicrafts, with several shops in three linear strips and an open space between them that would include some kiosks, seating areas, and sculptures made from the existing artefacts. The flooring paved with bricks would be spaced out and further be planted with native lawn to ensure the traditional village style.

The top of the handicraft centre should be used as café area, shaded with traditional grapevines and accessed by a steal staircase.

The second sub-zone is located in the northwestern part that consists of two huge barracks with no roof (building 18) should be reused to become a flower and herbs garden. The space between them should be designed to be stepped seating zone for outdoor gallery and market. Both zones would end at a barrack (building 19) which is proposed to be a workshop / gallery for custom-made items.

Overall, the regeneration strategy is mainly based on sustainability, which may result in cultural connectivity for the new young generation to keep their perception of history and heritage. Especially, most of the suggested functional components for the regeneration process were recommended by the facility's owner and the community. Thus, this proposal is focused on meeting their needs.

\section{CONCLUSIONS}

Urbanization and global economy are increasingly affecting our cities' structure. They lead to uniformity and degradation through abandoned sites and facilities. For that reason, sustainable regeneration is highly recommended as a process since it ensures attainment and continued satisfaction of the local communities. It particularly creates new values and impulses within an environmentally sensitive, economically viable, and socially acceptable context that results from a comprehensive analysis, which provides a good understanding of the opportunities and challenges of the context. Therefore, many programs and strategies should be developed. However, it is hard to provide universally suitable guidelines since every site has their own particular issues.

In conclusion, the following recommendations will improve the current practices:

a) a specialist for brownfield regeneration process management is needed to help achieving more successful projects;

b) suitable policy and funding are needed to maximize the goals of regeneration;

c) vision and strong leadership are needed to build up and maintain momentum during regeneration;

d) an appropriate control mechanism must be set up and public-private partnerships must be strengthened within a holistic approach.

Thus, sustainable brownfield regeneration would help transform devastated surfaces and landscapes into new attractive, inclusive, and multifunctional environment enhancing the character of the local community. So, more brownfield sites need to be rehabilitated and share their success. We hope this may help to the elaboration of some general guidelines and strategies for development, which could encourage Amman's municipality to create regulations for brownfield regeneration.

\section{REFERENCES}

Aljabi M. (2016), Rethinking Halted Investments Exploring the Potential of Interim Use in Amman. Master thesis of Science in Integrated Urbanism and Sustainable Design, Ain Shams University. URL: https://iusd.asu.edu.eg/wp-content/uploads/2017/o8/ 8-Al-Jabii.pdf

Alker S., Joy V., Roberts P., Smith N. (2000), The definition of brownfield. Journal of Environmental Planning and Management, 43(1), 49-69. DOI: https://doi.org/10.1080/09640560010766

Al-Rawashdeh S., Saleh B. (2006), Satellite Monitoring of Urban Spatial Growth in the Amman Area, Jordan. Journal of Urban Planning and Development, 132(4), 211216. DOI: https://doi.org/10.1061/(ASCE)0733-9488 (2006)132:4(211).

American Planning Association (APA) (2005), Legislative Priority: Brownfield. URL: http://www. planning.org/priorities/brownfield.htm.

Bagaeen S. (2006), Redeveloping Former Military Sites: Competitiveness, Urban Sustainability and Public Participation. Cities, 23(5), 339-352. DOI: 10.1016/ j.cities.2006.05.002

Bardos R. P., Jones S., Stephenson I., Menger P., Beumer V., Neonato F., Maring L., Ferber U., Track T., Wendler K. (2016), Optimizing value from the soft re-use of brownfield sites. The Science of the 
Total Environment, 563-564, 769-782. DOI: 10.1016/j.scitotenv.2015.12.002. ISSN: 0048-9697

Baskaya T. (2010), Ways to Sustainable Brownfield Regeneration in Istanbul, ITU A|Z, 7(2), 74-88. URL: https://www.journalagent.com/itujfa/pdfs/ITUJFA67699-DOSSIER_ARTICLES-TURER_BASKAYA.pdf.

Chen I. C., Tsai Y C., Ma. H. W. (2016), Toward sustainable brownfield redevelopment using life-cycle thinking. Sustainability, MDPI, Open Access Journal, 8(10), 994. DOI: https://doi.org/10.3390/su8100994

De Sousa A. (2002), Measuring the Public Costs and Benefits of Brownfield versus Greenfield Development in the Greater Toronto Area. Environment and Planning B: Urban Analytics and City Science, 29(2), 251-280. DOI: https://doi.org/10.1068\%2Fb1283

Frantal B., Kunk J., Novakova E., Klusacek P., Martinat S., Osman R. (2013), Location Matters! Exploring Brownfields Regeneration in a Spatial Context (a Case Study of the South Moravian Region, Czech Republic. Moravian Geographical Reports, Brno: ÚGN, 2013, 21(2), 5-19. URL: http://www.geonika.cz/ EN/research/ENMGRClanky/2013_2_FRANTAL.pdf.

Gegic A., Husukic E. (2017), Evaluation of the brownfield regeneration process: Case study of Sarajevo, Bosnia and Herzegovina. Journal of Urban Regeneration \& Renewal. 10(3), 276-285. ISSN (print): 1752-9638; ISSN (web): 1752-9646

Greenberg M., Lowrie K., Mayer H. (2001), Brownfield Redevelopment as a Smart Growth Option in the United States. The Environmentalist, 21. 129 143. DOI: https://doi.org/10.1023/A:1010684411938

Jordan Department of Statistics (JDS) (2016), Statistical Department of Jordan. JDS, Amman, Jordan. Kurtovića S., Siljkovićb B., Pavlovićc N. (2014), Methods of Identification and Evaluation of Brownfield Sites. International Journal of Research in Business and Social Science. 3(2), 105-120. URL: https://www.ssbfnet. com/ojs/index.php/ijrbs/article/view/171/173

Nogués S., Arroyo N. (2016), Alternative approach to prioritization of brownfield reclamation attending to urban development potentialities: Case study in a depressed industrial district in northern Spain. Journal of Urban Planning and Development, 142(1). DOI: https://doi.org/10.1061/(ASCE)UP.1943-5444.0000272 Rădulescu C. M., Ştefan O., Rădulescu G. M. T., Rădulescu A. T. G. M., Rădulescu, M. V. G. M. (2016), Management of stakeholders in urban regeneration projects. Case study: Baia-Mare, Transylvania. Sustainability, 8, 238. DOI: https://doi. org/10.3390/su8030238

Roberts P. W., Skyes H. (2000), Urban regeneration: A Handbook, Sage Publications. ISBN 978-0-7619-6716-3. URL: https://dl.urban-center.ir/ booklibrary/urbanregeneration.pdf.

Rosén L., Back P. E., Söderqvist T., Norrman J., Brinkhoff P., Norberg T., Volchko Y., Norin M., Bergknut M., Döberl G. (2015), SCORE: A novel multi-criteria decision analysis approach to assessing the sustainability of contaminated land remediation. Science of the Total Environment, 511, 621-638. DOI: https://doi.org/10.1016/j.scitotenv.2014.12.058

Tarawneh D. (2015), Brownfield Landscapes of Amman: Defining Typologies of Unnamed Terrains. Conference Paper "Transformation of Urban the Character of Arab Cities since the Late Last Century" Conference proceedings, German Jordan University GJU, Amman, 2224 April 2015. ISBN 978-1-904839-83-5

US Environmental Protection Agency (USEPA) (1997), Brownfield Economic Redevelopment Initiative. Washington DC: US Environmental Protection Agency. URL: https://nepis.epa.gov

United Nations Environment Program (UNEP) (2004), Guidelines for urban regeneration in the Mediterranean Region. Priority Actions Program, Regional Activity Centre Split. URL: https://www.papthecoastcentre.org

Yakhlef M., Abed A. (2019), Identification of Brownfield Sites Classification Typologies: Case Study of Amman, Jordan. Medwell Journal. 14(10), 3144 3149. DOI: 10.3923/jeasci.2019.3144.3149 